\title{
Intelligent methodologies in recursive data-based modelling
}

\author{
Esko K. Juuso \\ Control Engineering, Environmental and Chemical Engineering, Faculty of Technology, University of Oulu, Finland \\ esko.juusodoulu.fi
}

\begin{abstract}
Intelligent methodologies are beneficial in developing understandable multimodel simulation solutions. Nonlinear scaling extends these applications by facilitating compact nonlinear approaches already at the basic level. Composite local models can continue using linear methodologies for various case-based models. The flexible handling of the new structures and recursive tuning are the keys in adapting the systems in varying operating conditions. The recursive tuning of the scaling functions has two levels: smooth adaptation and strong shape changes. Fuzzy set systems further extend application areas of the models by combining composite local models in a flexible way. The extensions of the data-based methodologies are suitable for developing these adaptive applications via the following steps: variable analysis, linear models and intelligent extensions. Evolutionary computation is used in the tuning of the resulting complex models both the scaling and interactions. Complex problems are solved level by level to keep the domain expertise as an essential part.

Keywords: nonlinear systems, intelligent methods, recursive tuning, composite local models, linguistic equations
\end{abstract}

\section{Introduction}

In parametric models, the output is calculated as a linear combination of past inputs and past outputs. The output at time $t$ can depend on many signal values y from previous time instants. The signals should be chosen according to the appropriate time delays. Fuzzy and neural models are based on the same structures and input-output models. Another solution for the operation changes with time is to use time-dependent proportional hazard models, where exponential functions are used to activate new hazards.

Linear methodologies extended with principal components (Jolliffe, 2002; Gerlach et al., 1979) and semiphysical models (Ljung, 1999) provide a feasible solution for many applications. Nonlinearities have been handled commonly with interaction and quadratic terms (Box and Wilson, 1951). Linear parameter varying (LPV) extend these solutions to decomposed systems (Hjartarson et al., 2015; Theis et al., 2018).

Artificial neural networks (ANNs) could be extended to highly complex architectures for handling complicated interactions within different sources of varying data (Schmidhuber, 2015). Fuzzy set systems can handle knowledge-based information (Zadeh, 1965; Takagi and
Sugeno, 1985; Driankov et al., 1993; Dubois et al., 1999). Nonlinear dynamic models can be built by using fuzzy set systems (Babuška and Verbruggen, 2003) and low complexity neural networks (Sahoo et al., 2013). In hybrid dynamic models, local models need to be combined in complex systems (Sontag, 1981; Ljung, 2008; Jardine et al., 2006).

Linguistic equation (LE) models use the static mapping and NARX/Nonlinear AutoRegressive with eXogenous structures input models in the same way as fuzzy set systems and neural networks. The main difference is that the input and output variables are processed by a nonlinear scaling method, which originates from the membership functions used in fuzzy systems. (Juuso and Leiviskä, 1992; Juuso, 2004a) Constraints handling (Juuso, 2009a) and data-based analysis (Juuso and Lahdelma, 2010), improve possibilities to update the scaling functions recursively (Juuso, 2011). Different fuzzy approaches can be efficiently combined with LE models where the interactions between the scaled variables are linear (Juuso, 2014).

The LE approach integrates the knowledge-based systems, neural networks and evolutionary computation in the computational intelligence. Fuzzy set systems extend to parallel and contradictory phenomena in finding the operating areas, neural networks include more complex interactions, and evolutionary computation provide flexible optimization tools. The compact LE structures have many benefits: intelligent trend and deviation indices reveal changes and severity of them (Juuso, 2017). The nonlinear scaling is essential in dynamic models and prognostics, e.g. for predicting fatigue risk by using intelligent stress indices (Juuso and Ruusunen, 2013).

The recursive data analysis is based on two phases: first the parameters of the nonlinear scaling and then the model coefficients are analyzed to update the dynamic model. The aim is to keep the model equations unchanged as much as possible, i.e. interactions are not changing and the new situations are handled by changing the meanings of variables.

This paper focuses on the LE modelling approach based on nonlinear scaling (Section 2) enhanced with recursive solutions of updating the scaling and model interactions (Section 3). Composite local models and intelligent methodologies are combined in the multimodel LE simulation (Section 4). Possibilities of the new structures and recursive scaling are analyzed within a large set of previous applications in Section 5. Experiences and new pos- 
sibilities are discussed in Section 6 and conclusions and future research are presented in Section 7.

\section{Modelling methodologies}

Nonlinear scaling and steady-state statistical modelling with linear methodologies are the basis of the LE modelling. The fuzzy meanings of the variables are embedded in the nonlinear scaling. Interactions are analyzed by linear models and dynamic models are based on additional structures.

\subsection{Nonlinear scaling}

The nonlinearities of the process are handled by the nonlinear scaling of the variables. The scaling functions are monotonously increasing functions $x_{j}=f\left(X_{j}\right)$ where $x_{j}$ is the variable and $X_{j}$ the corresponding scaled variable. The function $f()$ consist of two second order polynomials, one for the negative values of $X_{j}$ and one for the positive values, respectively. The corresponding inverse functions $x_{j}=f^{-1}\left(X_{j}\right)$ based on square root functions are used for scaling to the range $[-2,2]$, denoted linguistification. In LE models, the results are scaled to the real values by using the function $f()$. (Juuso, 2004a)

The support area is defined by the minimum and maximum values of the variable, i.e. the support area is $\left[\min \left(x_{j}\right), \max \left(x_{j}\right)\right]$ for each variable $j, j=1, \ldots, m$. The central tendency value, $c_{j}$, divides the support area into two parts, and the core area is defined by the central tendency values of the lower and the upper part, $\left(c_{l}\right)_{j}$ and $\left(c_{h}\right)_{j}$, correspondingly. This means that the core area of the variable $j$ defined by $\left[\left(c_{l}\right)_{j},\left(c_{h}\right)_{j}\right]$ is within the support area. The parameters of the functions are extracted from measurements by using generalised norms and moments (Juuso and Lahdelma, 2010).

\subsection{Steady-state modelling}

The steady-state simulation models are linear multiple input, multiple output $(M I M O)$ models $\vec{y}=F(\vec{x})$, where the output vector $\vec{y}=\left(y_{1}, y_{2}, \ldots, y_{n}\right)$ is calculated by a linear function $F$ from the input vector $\vec{x}=\left(x_{1}, x_{2}, \ldots, x_{m}\right)$. Statistical modelling in its basic form uses linear regression for solving coefficients for a linear function. Linear methodologies are suitable for large multivariable systems. Quadratic and interactive terms are not used here. Principal components compress the data by reducing the number of dimensions with a minor loss of information (Jolliffe, 2002). Partial least squares regression (PLS) is an extension of these ideas (Gerlach et al., 1979). Known semi-physical models of inputs are important in linear modelling, see (Ljung, 1999).

The directions of the interactions analyzed with these methodologies are aimed to be valid in a wider area than the scaling functions of the model variables. The LPV modelling further extends the feasible areas of the model parameters.

\subsection{Dynamic modelling}

Data-driven modelling with parametric models, also known as identification (Ljung, 1999), is the key methodology in the dynamic modelling. In NARX models, the input and output values are chosen according to appropriate system orders. The regressor vector consists of a finite number of past inputs and outputs. The number may become too high in nonlinear systems. The dynamic structures are reduced in dynamic models based on fuzzy set systems or neural networks. The nonlinear scaling further reduces the number of input and output signals needed for all these systems.

\section{Recursive modelling}

Recursive data analysis facilitates the adaptation of the functions to changing operating conditions: the parameters of the scaling functions are obtained by using the earlier analyzed norms, also the orders of the norms can be re-analyzed if needed. Machine learning can be used to decide if the recursive updates are needed.

\subsection{Recursive nonlinear scaling}

The parameters of the nonlinear scaling functions can be recursively updated by including new equal sized subblocks in the calculations, i.e. the norm for several samples can be obtained as the norm of the norms of the individual samples:

$$
\left\|{ }^{K_{s} \tau} M_{j}^{p}\right\|_{p}=\left\{\frac{1}{K_{s}} \sum_{i=1}^{K_{s}}\left[\left({ }^{\tau} M_{j}^{p}\right)_{i}^{1 / p}\right]^{p}\right\}^{1 / p}=\left[\frac{1}{K_{s}} \sum_{i=1}^{K_{s}}\left[\left({ }^{\tau} M_{j}^{p}\right)_{i}\right]^{1 / p},\right.
$$

where $K_{S}$ is the number of samples $\left\{x_{j}\right\}_{i=1}^{N}$. In automation and data collection systems, the sub-blocks are normally used for arithmetic mean $(p=1)$. The norm values can be recursively updated with (1), and a new search for the orders is done only if the values change considerably (Juuso, 2011). The number of samples can be increasing or fixed with some forgetting, and weighting of the individual samples can be used in the analysis. The nonlinear scaling need to be done by a set of functions when the nonlinearities are very strong (Juuso and Lahdelma, 2010) and operating condition specific.

The analysis is the same for any combination of the subblocks. The central tendency value is chosen by the point where the skewness changes from positive to negative, i.e. $\gamma_{3}^{p}=0$. Then the data set is divided into two parts: a lower part and an upper part. The same analysis is done for these two data sets. The estimates of the corner points, $\left(c_{l}\right)_{j}$ and $\left(c_{h}\right)_{j}$, are the points where $\gamma_{3}^{p}=0$ for the lower and upper data sets, respectively. Since the search of these points is performed by using the order of the moment, the resulting orders $\left(p_{l}\right)_{j},\left(p_{0}\right)_{j}$ and $\left(p_{h}\right)_{j}$ are good estimates when additional data sets are used.

There is all the time an active set of scaling functions (Figure 1. The functions are tuned to appropriate operating areas by using the corresponding sets of data collected 


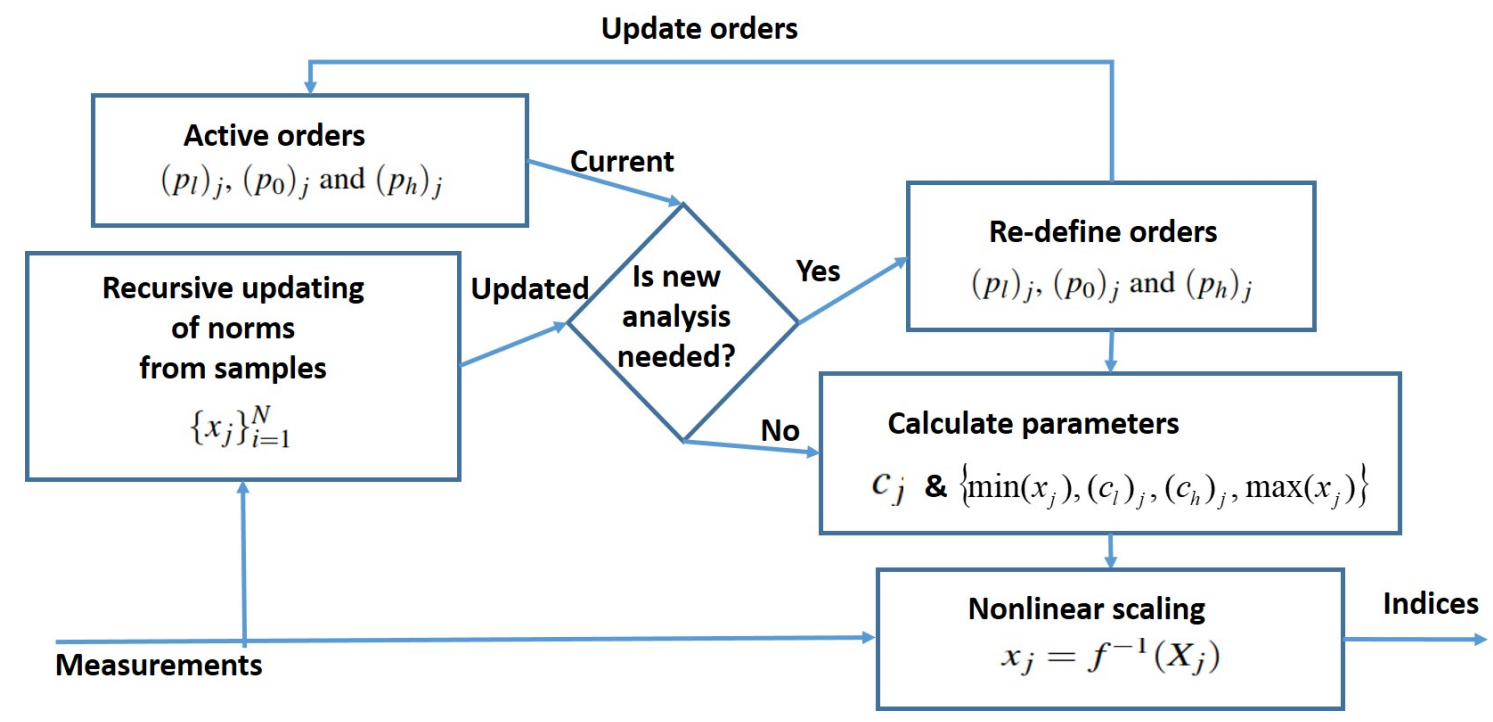

Figure 1. Recursive updating of scaling functions.

from the sub-blocks of the previous periods. The feasibility ranges should be wider for the working point variables. There are two levels of complexity for updating the scaling functions:

1. Individual scaling functions are smoothly adapted by using the existing norms (1) for the new data. This level requires only the values for the norms with the orders $\left(p_{l}\right)_{j},\left(p_{0}\right)_{j}$ and $\left(p_{h}\right)_{j}$.

2. The shape of the functions is modified by recursively updating the norm orders. In this case, the orders of the norms are updated from the data of the subblocks.

In both methodologies, the monotonous increase of the functions are checked and corrected if needed.

The scaling functions of the working point variables are aimed to cover the whole modelling area, i.e. they are analyzed with the same methodology, but for the set of the data includes several operating conditions.

\subsection{Interactions}

The model parameters can be updated by re-running the regression after the variables, whose scaling functions have been recursively updated, have been re-scaled. This is done for specific operating areas by using appropriate data. The procedure is the same for all submodels and working point models in any operating area.

Different operating areas can be analyzed with clustering to find feasible areas for local models. Cluster analysis provides hundreds of algorithms for the data-driven analysis (Xu and Tian, 2015). Iterations are needed since the clustering algorithms work better with linear systems, i.e. after nonlinear scaling.

\section{Multimodel LE simulation}

Multimodel approaches divide the problem into smaller parts for developing separate models for subprocesses or different stages in the process operation interconnected with process streams. Additional properties are achieved because equations and delays are allowed to vary between different submodels. The working areas can be defined by a separate working point model. The submodels are developed using the case-based modelling approach.

\subsection{Composite local models}

The composite local models use linear approximations of the nonlinear system in different neighbourhoods. If the partitioning is based on working point variables, the partitioning can be used in weighting the local models. In linear parameter varying (LPV) models, the matrices of the state-space models depend on an exogenous variable measured during the operation (Hjartarson et al., 2015; Theis et al., 2018). Piecewise affine (PWA) systems extend the local linear models to a polyhedral partition where the models can be state-space or parametric models (Christophersen, 2007). The model switches between different modes as the state variable varies over the partition. A high number of local models brings an overfitting risk.

Working point variables and their interactions can form a working point index for LPV models which are useful in smoothing the operation in varying operating conditions. The number of specific PWA systems can be reduced by using fuzzy set systems.

The LE models are defined by the parameters of the scaling functions and the coefficients of the interaction models. The idea of the exogenous variables can be used for these parameters, which opens a set of new modelling approaches for the nonlinear parameter (NPV) varying models where the exogenous variables are extended with 


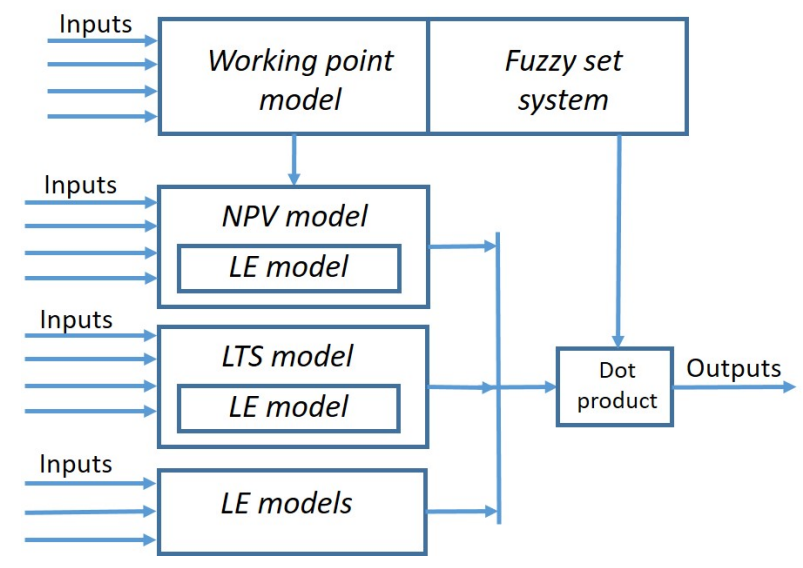

Figure 2. Multimodel LE system with a fuzzy decision module.

working point models (Figure 2).

\subsection{Intelligent systems}

The multimodel LE system consists of different types of submodels, a working point model and a fuzzy set system (Figure 2). The basic form includes a set of linguistic equations where each equation is specific for a certain phenomena which can be active in several operating conditions. The working point model calculates the degree of membership for each operating area which taken as a degree of membership for all the active equations of the case. Each model produces an alternative solution whose degree of membership $[0,1]$ is obtained by the fuzzy set system. All alternative solutions are aggregated and the response is defuzzified. Since the nonlinear scaling is operating condition specific, each active equation of each active operating condition produces an alternative result.

For certain phases of the process, the submodels in Figure 2 can be composite local models which extend the operating area of the submodels. The NPV models include a nonlinear parameter handling based on the LE working point models, i.e. the coefficients of the equations depend on the operating conditions. As much as possible is done with composite models and fuzzy methodologies are used for uncertainty and decisions.

Fuzzy set systems expand composite local models to partially overlapping models. Fuzzy models combine local modelling approaches and facilitate gradual changes. Takagi-Sugeno (TS) fuzzy models are based on linear submodels. The smoothing problems around the submodel borders need special techniques, e.g. smoothing maximum, or by making the area overlap very strong as it is done in the ANFIS method (Jang, 1993) which is practice a smoothing algorithm.

In the multimodel LE systems, a fuzzy decision system is used for selecting and weighting suitable nonlinear submodels for each situation (Figure 2). The fuzzy system based on a working point model or a single working point index provides several alternatives with different degrees of membership. In Linguistic Takagi-Sugeno fuzzy models (LTS), the fuzzy partition is defined with the same variables as the models and the nonlinearities are handled with the scaling functions and the interaction part with fuzzy set systems. The multimodel can be developed and tuned with the same methods as the normal TS models (Juuso, 2009b).

The fuzzy calculations are beneficial if there are parallel gradually activating phases or contradictory models. Decomposition is needed to extend the solutions to different subprocesses, process phases, phenomena and multiple operating conditions. In addition to spatial or logical blocks, the decomposed modelling can be based on different frequency ranges. The mixed systems may also include models based on the first principles.

In deep neural networks, an ensemble of redundant networks improves generalisation by averaging the process of creating multiple models and combining them to produce a desired output (Xiao et al., 2018). Naturally, this methodology could be used together with the nonlinear scaling. However, the fuzzy methodologies are preferred to keep the understanding of the subsystems strong.

\subsection{Evolutionary computing}

Evolutionary computing is widely used to tune intelligent systems which incorporate expert knowledge with data. Genetic algorithms (GA) are well suited for LE models based on nonlinear scaling and linear interactions. The scaling functions handle efficiently the parameter constraints of the monotonously increasing second order polynomials and the whole system is configured with a set of parameters. (Juuso, 2009a)

All the interactions within the multimodel LE system (Figure 2) are represented with compact linear equations whose coefficients can be included in the tuning based with genetic algorithms. The coefficients of the equations are re-analyzed for different operating conditions after updating the scaling functions.

The GA approach is flexible: an appropriate set of parameters is taken in the optimization and the performance is evaluated with the same methodology in all these levels. The recursive tuning of the scaling functions can be done with GAs without using the data-driven approach presented in Section 3.1.

\section{Applications}

Nonlinear scaling forms the basis for the LE modelling: an important benefit of the linear approach is that the models can be inverted, technically to any direction. The compact basic solution makes extensions to dynamic and casebased systems possible. Complex models for steady-state and dynamic systems can be built with the cascade and interactive structures.

Possibilities of the recursive tuning are analysed for the earlier applications presented in (Juuso, 2018). The topics of these applications are explained with more details in papers referred in this section. This paper focuses on how 
Table 1. Steady-state LE model applications.

\begin{tabular}{|c|c|c|c|}
\hline Case & Application area & Modelling & Recursive analysis \\
\hline Electric furnace & DSS for process design & $\begin{array}{l}\text { Nonlinear models transformed } \\
\text { to LE models and Interactions }\end{array}$ & Raw materials \\
\hline Lime kiln & Feedforward control & $\begin{array}{l}\text { Fuel feed in changing capacity } \\
\text { conditions }\end{array}$ & Fuel properties \\
\hline Solar collector field & Control adaptation & $\begin{array}{l}\text { Working point model: } \\
\text { irradiation, temperature, } \\
\text { difference, special cases } \\
\text { with fuzzy set systems }\end{array}$ & $\begin{array}{l}\text { Deterioration of } \\
\text { process condition }\end{array}$ \\
\hline Continuous cooking & Quality control & Quality forecasting & $\begin{array}{l}\text { Raw material } \\
\text { variations }\end{array}$ \\
\hline Fatigue & Stress contributions & $\begin{array}{l}\text { LE based stress-cycle curve: } \\
\text {-2nd order scaling for the stress } \\
\text {-logarithmic scaling for the cycles }\end{array}$ & $\begin{array}{l}\text { Deterioration of } \\
\text { process condition }\end{array}$ \\
\hline Water treatment & Feedforward control & $\begin{array}{l}\text { Turbidity for control } \\
\text { Forecasting residual aluminium }\end{array}$ & Seasonal effects \\
\hline Wastewater treatment & Diagnostics & Operating conditions & $\begin{array}{l}\text { Incoming wastewater } \\
\text { purity }\end{array}$ \\
\hline
\end{tabular}

Table 2. Dynamic LE model applications.

\begin{tabular}{|c|c|c|c|}
\hline Case & Application area & Modelling & Recursive analysis \\
\hline Gas furnace & Modelling & $\begin{array}{l}\text { Development and tuning: } \\
\text { training, validation, testing }\end{array}$ & Fluctuations \\
\hline Solar collector field & Controller tuning & $\begin{array}{l}\text { Time varying transport delay } \\
\text { Cloudy periods }\end{array}$ & $\begin{array}{l}\text { Deterioration } \\
\text { of the condition }\end{array}$ \\
\hline Fatigue & Forecasting fatigue risk & $\begin{array}{l}\text { Cumulative sum of scaled } \\
\text { stress contributions } \\
\text { Rolling mill, LHD machines }\end{array}$ & $\begin{array}{l}\text { Deterioration } \\
\text { process condition }\end{array}$ \\
\hline Water treatment & Controller tuning & $\begin{array}{l}\text { Water quality indicator } \\
\text { Water circulation } \\
\text { Drinking water }\end{array}$ & Seasonal effects \\
\hline Condition monitoring & Prognostics & Recursive tuning & $\begin{array}{l}\text { Deterioration } \\
\text { of the condition }\end{array}$ \\
\hline
\end{tabular}

the applications can be improved with the new structures and recursive tuning, see the column Recursive analysis in Tables 1, 2 and 3.

\subsection{Steady-state LE models}

Steady-state LE models are mainly used in adaptation and feedforward control (Table 1). In most cases, the models including only a single linear equation can be expanded in a straightforward way. The first LE model developed for designing submerged arc furnaces was an exception which used well known relations represented by five equations (Juuso and Leiviskä, 1992). Variations of raw material properties can be compared within additional levels. A steady-state LE model was developed from the process measurements in an early lime kiln control application where varying fuel properties require attention (Juuso et al., 1997). The working point model is an essential part of the model-based LE control of a solar power plant (Juuso and Yebra, 2013). During the years, the field condition has deteriorated, which has required recursive updates.

For continuous cooking, a LE model was developed for predicting the Kappa number, which is widely used quality variable (Leiviskä et al., 2001). Raw material variation should be taken into account.

Stress-cycle (S-N) curves, also known as Wöhler curves, are represented by a compact linguistic equation (Juuso and Ruusunen, 2013). Machine deterioration changes the meanings of the stress levels.

In drinking water applications, models have been developed for forecasting and control (Tomperi et al., 2013). Seasonal effects are important in these applications. Operating conditions are detected in diagnosing the wastewater treatment process (Juuso and Laakso, 2013). The strong effect of the biomass performance requires recursive up- 
Table 3. Decomposed LE model applications.

\begin{tabular}{|c|c|c|c|}
\hline Case & Application area & Modelling & Recursive analysis \\
\hline \multirow[t]{2}{*}{ Lime kiln } & Fuel quality & $\begin{array}{l}\text { Controller tuning by using } \\
\text { multiple models }\end{array}$ & $\begin{array}{l}\text { Fluctuations } \\
\text { in raw materials }\end{array}$ \\
\hline & Adaptive control & Working point control & $\begin{array}{l}\text { Varying operating } \\
\text { conditions are essential }\end{array}$ \\
\hline \multirow[t]{2}{*}{ Solar collector field } & $\begin{array}{l}\text { Controller tuning } \\
\text { for oil flow }\end{array}$ & $\begin{array}{l}\text { Models for different operating } \\
\text { conditions }\end{array}$ & $\begin{array}{l}\text { Irradiation } \\
\text { fluctuations }\end{array}$ \\
\hline & & Distributed parameter models & $\begin{array}{l}\text { Varying situations } \\
\text { at the collector field }\end{array}$ \\
\hline Batch cooking & On-line forecasting & $\begin{array}{l}\text { Three interactive models: alkali, } \\
\text { lignin and dissolved solids }\end{array}$ & $\begin{array}{l}\text { New structure for } \\
\text { interactions and phases }\end{array}$ \\
\hline $\begin{array}{l}\text { Fluidised bed } \\
\text { granulation }\end{array}$ & Forecasting & $\begin{array}{l}\text { Three interactive models: } \\
\text { temperature, humidity } \\
\text { and granular size }\end{array}$ & $\begin{array}{l}\text { New structure } \\
\text { interactions and phases }\end{array}$ \\
\hline $\begin{array}{l}\text { Fed-batch } \\
\text { fermentation }\end{array}$ & On-line forecasting & $\begin{array}{l}\text { Submodels of three growth phases, } \\
\text { each including three interactive } \\
\text { models } \\
\text { Totally nine interactive models }\end{array}$ & $\begin{array}{l}\text { New structure for } \\
\text { interactions and phases } \\
\text { Activation and decline } \\
\text { of partially simultaneous } \\
\text { processes }\end{array}$ \\
\hline Wastewater treatment & $\begin{array}{l}\text { Detection of operating } \\
\text { conditions }\end{array}$ & $\begin{array}{l}\text { Three submodels: load, treatment } \\
\text { and settling } \\
\text { Trend analysis }\end{array}$ & Biomass performance \\
\hline
\end{tabular}

dates.

\subsection{Dynamic LE models}

The basic dynamic LE model is represented by a compact parametric model

$$
Y(t)+a_{1} Y(t-1)=b_{1} U\left(t-n_{k}\right)+e(t)
$$

for the scaled variables $Y$ and $U$. More complicated inputoutput NARX models containing are simplified by using the nonlinear scaling. The models can have an appropriate number of variables. The approach was first tested in a gas furnace data provided by (Box and Jenkins, 1970). The dynamic models of the solar plant are based on test campaigns, which cannot be planned in detail because of changing weather conditions (Juuso, 2003a). The irradiation changes and varying cloudy conditions have strong effects.

The basic dynamic flotation model is the core of the quality indicator in water treatment (Joensuu et al., 2005). A dynamic LE model has been used for the fatigue prediction in (Juuso and Ruusunen, 2013). In all these models, only one equation is needed. The applications are indirect measurements and controller tuning (Table 2). Drinking water applications focus on model-based control and forecasting (Tomperi et al., 2016). The multimodel structures (Juuso et al., 2009) and trend analysis (Tomperi et al., 2017) are important in the wastewater treatment.

The new structure and recursive tuning allow the handling of deterioration of condition, fluctuations and seasonal effects (Table 2). The recursive tuning was already used in the condition monitoring application. In most real applications, the changes are too fast to use recursive updates online. The offline analysis expands the libraries for predefined adaptation.

\subsection{Decomposition in LE models}

The multimodel LE system can include several submodels and complex interactions (Table 3). All basic submodels are represented by (2) extended to an appropriate number of variables. The model with a fuzzy decision module was first used for a lime kiln (Juuso, 1999) and then for a solar thermal power plant (Juuso, 2003a). The lime kiln model had six operating areas defined by the production level and the trend of the fuel feed (increasing, decreasing). The model of the collector field includes four operating areas: start-up, low, normal and high operation. Additional fuzzy models have been developed for special situations (Juuso et al., 2000). In these cases, the decision module use working point variables are provides specific degrees of membership for all the submodels. Recursive tuning is needed only for specific submodels in new situations.

Interactive dynamic models were needed in several cases: batch cooking (Juuso, 2003b), fluidised bed granulator (Mäki et al., 2004), industrial fed-batch fermenter (Saarela et al., 2003) and wastewater treatment (Juuso et al., 2009). Linguistic equations, neural networks and fuzzy modelling with several variants have been compared by using the process data obtained from the fed-batch fermenter. The LE models are sufficiently compact to be used in the complex system presented in Figure 2. 
The phases and interactive submodels make the modelling complicated (Table 3). Additional requirements were recently detected for the fed-batch fermentation case, where the activation and decline of different phenomena need be taken into account (Juuso, 2019). The new structure of integrating composite submodels and intelligent systems (Figure 2) and recursive tuning provide improvements for the handling of interactions and phases as well as the fluctuations of fuel properties and performance of biomass in the treatment.

Phenomenological models can be integrated with these solutions through a data-driven model which provides the parameters needed in the models of phenomena.

\subsection{Distributed parameter LE models}

In the distributed parameter models, the solar collector field is divided into modules, where the dynamic LE models are applied in a distributed way (Juuso, 2004b). The same single equation model (2) with an appropriate number of variables is used in all modules. Element locations for partial differential equations (PDEs) are defined by the flow rate. In cloudy conditions, the heating effect can be strongly uneven.

The new structure and recursive tuning provide possibilities to handle local variations of the collector field which become important if the temperature increase is high (Table 3).

\section{Discussion}

The nonlinear scaling methodology is the key in the extensions of the linear methodologies. The scaling can be recursively updated and used in both steady-state and dynamic applications with additional structures. Several steady-state and dynamic models are combined with fuzzy set systems. Distributed parameter systems can use the same algorithms. In the applications discussed in Section 5 , the scaling functions were developed before the current data-based analysis. New structures and recursive tuning provide additional possibilities for them.

The variable specific recursive analysis of the parameters of the scaling functions is feasible throughout the modelling. This is important in the smooth adaptation of the submodels and introducing models for new operating areas. The interactions are tried to keep unchanged but can be retuned when needed.

The multimodel structure facilitates deep learning extensions. All parameters of the multimodel LE systems, including any subsystem or model, can be updated with the same genetic tuning. Constraints are taken into account in the coding which means that penalties are not needed in the optimisation.

The recursive approach is in this paper presented as an offline analysis. The methodology is applicable for the online analysis as well. Statistical process control provides additional tools for detecting changes, anomalies and novelties. The existing scaling functions provide a basis for assessing the quality of new data: outliers should be excluded, but the suspicious values may mean that the operating conditions are changing and the support area should be extended. The online analysis could be used in some subsystems in specific operating areas.

\section{Conclusions and future research}

The nonlinear scaling approach extends the application areas of linear methodologies to nonlinear modelling: the meanings of variables and interactions are analysed either sequentially or simultaneously. Local nonlinear models and recursive tuning reduce the number of the local models. Intelligent methodologies are essential parts of the system: the close connection to the fuzzy set systems provides a good basis for understandable models and evolutionary computation is used in the tuning of the resulting complex models. Composite local models and intelligent systems can be efficiently combined. The basic models are compact and additional properties, including dynamics, uncertainty and decomposition, are included if needed. The recursive analysis is a basis for future research in various applications discussed in this paper.

\section{References}

R. Babuška and H. Verbruggen. Neuro-fuzzy methods for nonlinear system identification. Annual Reviews in Control, 27 (1):73-85, 2003.

G. E. P. Box and G. M. Jenkins. Time Series Analysis, Forecasting and Control. Holden Day, San Francisco, 1970.

G. E. P. Box and K. B. Wilson. On the experimental attainment of optimum conditions. Journal of the Royal Statistical Society. Series B, 13(1):1-45, 1951.

F. J. Christophersen. Piecewise Affine Systems. In M. M. Gupta and T. Yamakawa, editors, Optimal Control of Constrained Piecewise Affine Systems, Lecture Notes in Control and Information Sciences, volume 359, pages 39-42. Springer, Berlin, Heidelberg, 2007. doi:10.1007/978-3-540-72701-9_4.

D. Driankov, H. Hellendoorn, and M. Reinfrank. An Introduction to Fuzzy Control. Springer, Berlin, Germany, 1993.

D. Dubois, H. Prade, and L. Ughetto. Fuzzy logic, control engineering and artificial intelligence. In H. B. Verbruggen, H.J. Zimmermann, and R. Babuska, editors, Fuzzy Algorithms for Control, International Series in Intelligent Technologies, pages 17-57. Kluwer, Boston, 1999.

R. W. Gerlach, B. R. Kowalski, and H. O. A. Wold. Partial least squares modelling with latent variables. Anal. Chim. Acta, 112(4):417-421, 1979.

A. Hjartarson, P. Seiler, and A. Packard. LPVTools: A toolbox for modeling, analysis, and synthesis of parameter varying control systems. IFAC-PapersOnLine, 48(26):139-145, 2015. URL www. scopus. com.

J.-S. R. Jang. ANFIS: Adaptive-Network-based Fuzzy Inference Systems. IEEE Transactions on Systems, Man, and Cybernetics, 23(3):665-685, 1993. 
A. K. S. Jardine, D. Lin, and D. Banjevic. A review on machinery diagnostics and prognostics implementing conditionbased maintenance. Mechanical Systems and Signal Processing, 20(7):1483-1510, 2006.

I. Joensuu, M. Piironen, and E. Juuso. Dynamic simulator for dosing of water treatment chemicals. Computer-aided chemical engineering, European Symposium on Computer Aided Process Engineering-15 (Escape-15), Barcelona, Spain, May 29 - June 1, 2005, 20A:301-306, 2005.

I. T. Jolliffe. Principal Component Analysis. Springer, New York, 2 edition, 2002. 487 pp.

E. Juuso and I. Laakso. Hybrid LE systems for simulation of an activated sludge process. In Proceedings - 8th EUROSIM Congress on Modelling and Simulation, EUROSIM 2013, 10-13 September, 2013, Cardiff, UK, pages 124-129, 2013. doi:10.1109/EUROSIM.2013.32.

E. Juuso and S. Lahdelma. Intelligent scaling of features in fault diagnosis. In 7th International Conference on Condition Monitoring and Machinery Failure Prevention Technologies, CM 2010 - MFPT 2010, 22-24 June 2010, Stratfordupon-Avon, UK, volume 2, pages 1358-1372, 2010. URL WwW. scopus. com.

E. Juuso and M. Ruusunen. Fatigue prediction with intelligent stress indices based on torque measurements in a rolling mill. In 10th International Conference on Condition Monitoring and Machinery Failure Prevention Technologies, CM 2013 MFPT 2013, 18-20 June 2013, Krakow, Poland, volume 1, pages 460-471, 2013. URL www. scopus . com.

E. Juuso, T. Latvala, and I. Laakso. Intelligent analysers and dynamic simulation in a biological water treatment process. In I. Troch and F. Breitenecker, editors, 6th Vienna Conference on Mathematical Modelling - MATHMOD 2009, February 11-13, 2009, Argesim Report no. 35, pages 999-1007. Argesim, 2009. ISBN 978-3-901608-35-3.

E. K. Juuso. Intelligent dynamic simulation of a lime kiln with linguistic equations. In H. Szczerbicka, editor, ESM'99: Modelling and Simulation: A tool for the Next Millenium, 13th European Simulation Multiconference, Warsaw, Poland, June 1-4, 1999, pages 395-00, Delft, The Netherlands, 1999. SCS.

E. K. Juuso. Intelligent dynamic simulation of a solar collector field. In A. Verbraeck and V. Hlupic, editors, Simulation in Industry, 15th European Simulation Symposium ESS 2003, pages 443-449. SCS, Gruner Druck, Erlangen, Germany, 2003a.

E. K. Juuso. Intelligent dynamic simulation of batch cooking. In 44th Scandinavian Conference on Simulation and Modeling SIMS 2003, September 18 -19, 2003, pages 163-169. Malardalen University, Västeras, Sweden, 2003b.

E. K. Juuso. Integration of intelligent systems in development of smart adaptive systems. International Journal of Approximate Reasoning, 35(3):307-337, 2004a. doi:10.1016/j.ijar.2003.08.008.
E. K. Juuso. Dynamic simulation of a solar collector field with intelligent distributed parameter models. In B. Elmegaard, Jon Sporring, Kenny Erleben, and Kim Soerensen, editors, Proceedings of SIMS 2004 - the 45th Scandinavian Conference on Simulation and Modelling, September 23-24, Copenhagen, Denmark, pages 141-153. DTU, Lungby, Denmark, 2004b.

E. K. Juuso. Tuning of large-scale linguistic equation (LE) models with genetic algorithms. In M. Kolehmainen, editor, Revised selected papers of the International Conference on Adaptive and Natural Computing Algorithms - ICANNGA 2009, Kuopio, Finland, Lecture Notes in Computer Science, volume LNCS 5495, pages 161-170. Springer-Verlag, Heidelberg, 2009a. doi:10.1007/978-3-642-04921-7_17.

E. K. Juuso. Development of multiple linguistic equation models with Takagi-Sugeno type fuzzy models. In J. P. Carvalho, D. Dubois, U. Kaymak, and J. C. M. Sousa, editors, Proceedings of 2009 IFSA World Congress / 2009 EUSFLAT Conference, July 20-24, 2009, Lisboa, Portugal, pages 1779-1784. IFSA-EUSFLAT, 2009b. http://www.eusflat.org/publications_proceedings_IFSAEUSFLAT_2009.php.

E. K. Juuso. Recursive tuning of intelligent controllers of solar collector fields in changing operating conditions. In S. Bittani, A. Cenedese, and S. Zampieri, editors, Proceedings of the 18th World Congress The International Federation of Automatic Control, Milano (Italy) August 28 - September 2, 2011, pages 12282-12288. IFAC, 2011. doi:10.3182/20110828-6-IT-1002.03621.

E. K. Juuso. Intelligent methods in modelling and simulation of complex systems. Simulation Notes Europe SNE, 24(1):1-10, 2014. doi:10.11128/sne.24.on.102221.

E. K. Juuso. Intelligent performance analysis with a natural language interface. Management Systems in Production Engineering, 25(3):168-175, 2017. doi:10.1515/mspe-20170025 .

E. K. Juuso. Intelligent multimodel simulation in decomposed systems. In L. E. Øi, T. Komulainen, R. T. Bye, and L. O. Nord, editors, Proceedings of The 59th Conference on Simulation and Modelling (SIMS 59), 26-28 September 2018, Oslo Metropolitan University, Norway, number 153 in Linköping Electronic Conference Proceedings, pages 308-315. Linköping University Electronic Press, 2018. doi:10.3384/ecp18153308.

E. K. Juuso. Intelligent dynamic simulation of fed-batch fermentation processes. In E. Dahlquist, E. Juuso, B. Lie, and L. Eriksson, editors, Proceedings of The 60th Conference on Simulation and Modelling (SIMS 60), 13-16, 2019, Västerås, Sweden, number 170 in Linköping Electronic Conference Proceedings, pages 132-138. Linköping University Electronic Press, Linköpings universitet, 2019. doi:10.3384/ecp20170132.

E. K. Juuso and K. Leiviskä. Adaptive expert systems for metallurgical processes. In S.-L. Jämsä-Jounela and A. J. Niemi, editors, Expert Systems in Mineral and Metal Processing, IFAC Workshop, Espoo, Finland, August 26-28, 1991, IFAC Workshop Series, 1992, Number 2, pages 119-124, Oxford, UK, 1992. Pergamon. 
E. K. Juuso and L. J. Yebra. Model-based intelligent control of a solar energy collector field. In Proceedings - 8th EUROSIM Congress on Modelling and Simulation, EUROSIM 2013, 10-13 September, 2013, Cardiff, UK, pages 513-518, 2013. doi:10.1109/EUROSIM.2013.92. URL www . scopus . com.

E. K Juuso, T. Ahola, and K. Leiviskä. Fuzzy modelling of a rotary lime kiln using linguistic equations and neurofuzzy methods. In L. Foulloy, editor, Proceedings of the 3rd IFAC Symposium on Intelligent Components and Instruments for Control Applications - SICICA'97, Annecy, France, June 9-11, 1997, pages 579-584. Pergamon, 1997. ISBN 9780080426082 .

E. K. Juuso, D. Schauten, T. Slawinski, and H. Kiendl. Combination of linguistic equations and the fuzzy-ROSA method in dynamic simulation of a solar collector field. In L. Yliniemi and E. Juuso, editors, Proceedings of TOOLMET 2000 Symposium - Tool Environments and Development Methods for Intelligent Systems, Oulu, April 13-14, 2000, pages 63-77, Oulu, 2000. Oulun yliopistopaino.

K. Leiviskä, E. Juuso, and A. Isokangas. Intelligent modelling of continuous pulp cooking. In K. Leiviskä, editor, Industrial Applications of Soft Computing, Studies in Fuzziness and Soft Computing, pages 147-158. Springer, Heidelberg, 2001. doi:10.1007/978-3-7908-1822-2_10.

L. Ljung. System Identification - Theory for the User. Prentice Hall, Upper Saddle River, N.J., 2nd edition, 1999.

L. Ljung. Perspectives on system identification. In M. J. Chung and P. Misra, editors, Plenary papers, milestone reports \& selected survey papers, 17th IFAC World Congress, Seoul, Korea, July 6-11, 2008, pages 47-59. IFAC, 2008. http://www.ifac-papersonline.net/.

T. Mäki, E. Juuso, and K. Leiviskä. Fuzzy modelling and dynamic simulation of a fluidised bed granulator. In K. Leiviskä, editor, Proceedings of AFNC'04 - the 2nd IFAC Workshop on Advanced Fuzzy/Neural, September 16-17, 2004, Oulu, Finland, pages 133-138. Finnish Automation Society, Helsinki, 2004.

U. Saarela, K. Leiviskä, E. Juuso, and A. Kosola. Modelling of a fed-batch enzyme fermentation process. In IFAC International Conference on Intelligent Control Systems and Signal Processing. Faro, Portugal, April 8-11, 2003. IFAC, 2003.

H.K. Sahoo, P.K. Dash, and N.P. Rath. Narx model based nonlinear dynamic system identification using low complexity neural networks and robust $\mathrm{H} \infty$ filter. Applied Soft Computing, 13(7):3324 - 3334, 2013. ISSN 1568-4946. doi:10.1016/j.asoc.2013.02.007.

J. Schmidhuber. Deep learning in neural networks: An overview. Neural Networks, 61 (Supplement C):85 - 117, 2015. ISSN 0893-6080. doi:https://doi.org/10.1016/j.neunet.2014.09.003. URL http://www.sciencedirect.com/science/ article/pii/s0893608014002135.

E. Sontag. Nonlinear regulation: The piecewise linear approach. IEEE Transactions Automatic Control, 26(2):346-358, 1981.
T. Takagi and M. Sugeno. Fuzzy identification of systems and its applications to modeling and control. IEEE Transactions on Systems, Man, and Cybernetics, 15(1):116-132, 1985.

J. Theis, P. Seiler, and H. Werner. LPV model order reduction by parameter-varying oblique projection. IEEE Transactions on Control Systems Technology, 26(3):773-784, 2018. URL wWw. scopus. com.

J. Tomperi, E. Juuso, and K. Leiviskä. Hybrid LE systems for simulation of an activated sludge process. In Proceedings -8th EUROSIM Congress on Modelling and Simulation, EU-ROSIM 2013, 10-13 September, 2013, Cardiff, UK, pages 118-123, 2013. doi:10.1109/ EUROSIM.2013.31. URL www. scopus. com.

J. Tomperi, E. Juuso, and K. Leiviskä. Early warning of changing drinking water quality by trend analysis. Journal of Water and Health, 14(3):433-442, 2016. doi:10.2166/wh.2016.330.

J. Tomperi, E. Juuso, A. Kuokkanen, and K. Leiviskä. Monitoring a municipal wastewater treatment process using a trend analysis. Environmental Technology (United Kingdom), pages 1-10, 2017. doi:10.1080/09593330.2017.1375026.

Y.-W. Xiao, J. Wu, Z.-G. Lin, and X.-D. Zhao. A deep learningbased multi-model ensemble method for cancer prediction. Computer Methods and Programs in Biomedicine, 153:1 - 9, 2018. ISSN 0169-2607. doi:10.1016/j.cmpb.2017.09.005.

D.-K. Xu and Y.-J. Tian. A comprehensive survey of clustering algorithms. Annals of Data Science, 2(2):165-193, Jun 2015. ISSN 2198-5812. doi:10.1007/s40745-015-0040-1.

L. A. Zadeh. Fuzzy sets. Information and Control, 8(June): 338-353, 1965. 